\title{
A COMPARATIVE STUDY OF THE EFFECTS OF INTRATHECAL MIDAZOLAM AND FENTANYL AS ADDITIVES TO INTRATHECAL HYPERBARIC BUPIVACAINE (0.5\%) FOR SPINAL ANAESTHESIA
}

\author{
K. Kurmanadh ${ }^{1}$, K. Srilakshmi²
}

${ }^{1}$ Associate Professor, Department of Anaesthesiology, Visakha Institute of Medical Sciences (VIMS), Visakhapatnam. ${ }^{2}$ Associate Professor, Department of Anaesthesiology, Visakha Institute of Medical Sciences (VIMS), Visakhapatnam.

\section{ABSTRACT}

\section{BACKGROUND}

Spinal anaesthesia by $0.5 \%$ hyperbaric bupivacaine is characterised by a relatively rapid onset of action with duration of anaesthesia for approximately 3 hours and profound motor blockade. Even though it provides effective pain relief in the initial postoperative period, these patients need rescue analgesia after 3 hours. To maximise postoperative analgesia, several adjuvants, such as opioids, Clonidine, Ketamine, neostigmine, etc. have been added to spinal local anaesthetics. Preservative free midazolam is also being used as an adjuvant to prolong the duration of block.

Aims and Objectives- The present study was undertaken to compare the effects of intrathecal midazolam (1 mg) and fentanyl (25 micrograms) as additives to intrathecal hyperbaric bupivacaine $(0.5 \%)$ for spinal anaesthesia.

\section{MATERIALS AND METHODS}

A prospective double blind randomised controlled study was carried out on 100 adult patients. Patients were randomly selected by envelope method into two groups of 50 in each. Group "BF" - Bupivacaine plus fentanyl group; Group "BM" - Bupivacaine plus midazolam group.

\section{RESULTS}

There were no differences in the onset and duration of sensory blockade, and durations of complete and effective analgesia, when fentanyl 25 micrograms or midazolam $1 \mathrm{mg}$ was used as additive to intrathecal hyperbaric bupivacaine for spinal anaesthesia. But midazolam was associated with fewer side effects compared to fentanyl.

\section{CONCLUSION}

Intrathecal combination of bupivacaine and midazolam offers same advantages in terms of onset and duration of sensory blockade and durations of complete and effective analgesia with fewer side effects compared to bupivacaine and fentanyl.

\section{KEYWORDS}

Midazolam, Fentanyl, Adjuvants, Bupivacaine, Spinal Anaesthesia.

HOW TO CITE THIS ARTICLE: Kurmanadh K, Srilakshmi K. A comparative study of the effects of intrathecal midazolam and fentanyl as additives to intrathecal hyperbaric bupivacaine (0.5\%) for spinal anaesthesia. J. Evolution Med. Dent. Sci. 2017;6(38): 3061-3064, DOI: 10.14260/Jemds/2017/660

\section{BACKGROUND}

Pain $^{1}$ during postoperative period is a cause of concern not only for the patient, but also for the surgeon and the anaesthesiologist. Postoperative pain control is generally best managed by anaesthesiologist because they offer regional techniques of anaesthesia and pharmacological expertise in analgesics. Apart from obvious humanitarian reasons, effective postoperative analgesia results in decreased incidence of respiratory, cardiovascular complications, early ambulation and discharge from hospital. Spinal anaesthesia by $0.5 \%$ hyperbaric bupivacaine is characterised by a relatively rapid onset of action with duration of anaesthesia for approximately 2-3 hours and profound motor blockade. In these patients, rescue analgesia is necessary after 2-3 hours even though it provides effective pain relief in the initial postoperative period.

Financial or Other, Competing Interest: None.

Submission 19-04-2017, Peer Review 02-05-2017,

Acceptance 04-05-2017, Published 11-05-2017.

Corresponding Author:

Dr. K. Srilakshmi,

Associate Professor,

Department of Anaesthesiology,

VIMS, Arilova, Health City,

Visakhapatnam, Andhra Pradesh.

E-mail: dr.ksl.md@gmail.com

DOI: $10.14260 /$ jemds $/ 2017 / 660$

(c) $(7)$
To maximise postoperative analgesia, several adjuvants, such as opioids ${ }^{2}$ Clonidine, ${ }^{3}$ ketamine, ${ }^{4}$ neostigmine, ${ }^{5}$ etc. have been added to spinal local anaesthetics. Preservative free midazolam is also being used in recent times as an additive to intrathecal hyperbaric bupivacaine to prolong the quality and duration of analgesia. It is associated with fewer side effects compared to neuraxial opioids.

Fentanyl, a highly lipophilic opioid, has rapid onset of action following intrathecal administration. Fentanyl has side effects like pruritus, nausea and vomiting and even a possible serotonin syndrome related to intrathecal fentanyl has been reported. ${ }^{6}$ Duration of the effect of intrathecal fentanyl is dose dependent. In spinal anaesthesia, hyperbaric bupivacaine combined with fentanyl 6.25 micrograms facilitates precise perioperative analgesia 7 . The present study was undertaken to compare the effects of intrathecal midazolam (1 mg) and fentanyl (25 micrograms) as additives to intrathecal hyperbaric bupivacaine $(0.5 \%)$ for spinal anaesthesia.

\footnotetext{
Aims and Objectives

This study is undertaken to evaluate and compare the effects of intrathecal midazolam (1 $\mathrm{mg}$ ) and fentanyl (25 micrograms) as additives to intrathecal hyperbaric bupivacaine $(0.5 \%)$ with regards to-

- Onset and duration of sensory block.

- Duration of complete and effective analgesia.
} 
- $\quad$ Side effects associated with the drugs.

\section{MATERIALS AND METHODS}

This was a randomised prospective controlled study done to compare and evaluate the effects of intrathecal midazolam (1 $\mathrm{mg}$ ) and fentanyl (25 micrograms) as additives to intrathecal hyperbaric bupivacaine $(0.5 \%)$ for spinal anaesthesia during the period of November 2016 to March 2017. The study was performed only after obtaining a clear permission from the Institutional Ethics Committee of Visakha Institute of Medical Sciences, Visakhapatnam.

A prospective, double blind, randomised controlled study was carried out on 100 adult patients. Patients were randomly selected by envelope method into two groups of 50 each. SSPS 2.0 and Microsoft excel are the software used for computing the values and independent $t$ test are used.

- Group "BF" - Bupivacaine plus fentanyl group.

- Group "BM" - Bupivacaine plus midazolam group.

\section{Inclusion Criteria}

1. ASA grade I and II patients.

2. Age group of $18-60$ years.

3. Patients giving valid informed consent.

4. Those patients scheduled to undergo elective lower abdominal, lower extremity, gynaecological or urological surgeries under subarachnoid block.

\section{Exclusion Criteria}

1. Patients physically dependent on narcotics.

2. Patients with history of drug allergy.

3. Patients with gross spinal abnormality, localised skin sepsis, haemorrhagic diathesis or neurological involvement/diseases.

4. Head injury cases.

5. Patients with cardiac, pulmonary, hepatic or renal disorders.

6. Patients with peripheral neuropathy.

7. Patients having inadequate subarachnoid blockade and who are later supplemented by general anaesthesia.

8. Obstetric cases for lower segment caesarean section because of drug dosage discrepancy.

9. Body weight $>100 \mathrm{Kg}$.

10. Height less than $150 \mathrm{~cm}$.

11. Chronic pain at puncture site.

12. Patients who are unable to communicate.

The procedure of subarachnoid block was explained and the informed consent was taken from the patients. They were premedicated with Tab. Alprazolam $0.5 \mathrm{mg}$ and Tab. Ranitidine $150 \mathrm{mg}$ orally 12 hours before giving spinal anaesthesia.

In the preoperative room, intravenous line was secured and the patients were preloaded with $15 \mathrm{~mL} / \mathrm{kg}$ Ringers lactate, 30 minutes prior to spinal anaesthesia. After shifting to operation room, standard monitoring was carried out in the form of pulse oximetry, ECG and non-invasive arterial blood pressure monitoring. In each case, spinal anaesthesia was performed under strict aseptic precautions by inserting 26 gauge Quincke spinal needle into subarachnoid space at L3-4 interspace with the patient in left lateral position and the study solution was injected over 15-20 seconds.
- Patients belonging to group BF received $3 \mathrm{~mL}(15 \mathrm{mg})$ of hyperbaric bupivacaine $(0.5 \%)+0.5 \mathrm{~mL}$ (25 micrograms) of fentanyl.

- Patients of group BM received $3 \mathrm{~mL}$ (15 mg) of hyperbaric bupivacaine $(0.5 \%)+0.2 \mathrm{~mL}(1 \mathrm{mg})$ of preservative free midazolam $+0.3 \mathrm{~mL}$ of normal saline.

After injection, patient was immediately turned to supine position. Pulse rate, respiratory rate, arterial blood pressure and oxygen saturation were recorded every $5 \mathrm{~min}$. for first 10 minutes, every $10 \mathrm{~min}$. for next half an hour and then every 15 minutes in the intra-operative period. Bolus doses of Inj. Mephentermine $6 \mathrm{mg}$ IV were given to maintain arterial blood pressure within $20 \%$ of base line and Inj. Atropine 0.6 mg IV was given when the patient developed bradycardia (PR< 50 beats/min.).7,8 No other sedative or analgesic was given in the study period. Sensory block was assessed by pinpricks in midclavicular line bilaterally using 27-gauge hypodermic needle. The onset of sensory block was considered as the time taken from intrathecal injection to the highest level of the sensory block. ${ }^{9}$

The duration of sensory block was taken from the time of intrathecal injection to regression of the level of sensory block to L1 dermatome. ${ }^{7}$ Postoperative analgesia was assessed using a visual analogue scale (VAS). The patient was asked to mark on a $10 \mathrm{~cm}$ horizontal scale with no pain corresponding to 0 at one end and the worst unbearable excruciating pain to 10 at the other end. This was explained to the patient in his vernacular language. The patient's mark of severity of pain on the line was measured.

\section{VAS Score Intensity of Pain}

0-2 No pain to slight pain.

2-5 Mild pain.

5-7 Moderate pain.

7-9 Severe pain.

10 Worst possible pain.

The duration of complete analgesia was taken for the time of intrathecal drug administration to the first report of pain. The duration of effective analgesia was taken from the time of intrathecal drug administration to the time of first supplementation of rescue analgesic.

Sedation scores were assessed every 15 minutes both intra and postoperatively using modified Wilson Sedation Score ${ }^{10}$ which is as follows:

\section{Sedation Score - Patient's Condition}

$1=$ Fully awake and oriented.

2 = Drowsy.

$3=$ Eyes closed but arousable to command.

$4=$ Eyes closed but arousable to mild physical stimulation (Earlobe tug).

$5=$ Eyes closed but unarousable to mild physical stimulation.

Postoperatively, monitoring of vital signs, VAS scores and sedation scores were continued every 15 minutes until the time of regression of sensory block to L1 dermatome. The incidence of hypotension (Arterial blood pressure $<20 \%$ of baseline), bradycardia, pruritus, nausea, vomiting and urinary retention were monitored in the recovery room and then shifted to the ward. 


\section{RESULTS}

Hundred adult patients of ASA physical status I \& II in the age group of 18 years to 60 years, of either sex, posted for elective lower limb, lower abdominal, gynaecological and urological surgeries under spinal anaesthesia were selected for the study.

Type of Surgeries Performed on Patients in the study groups

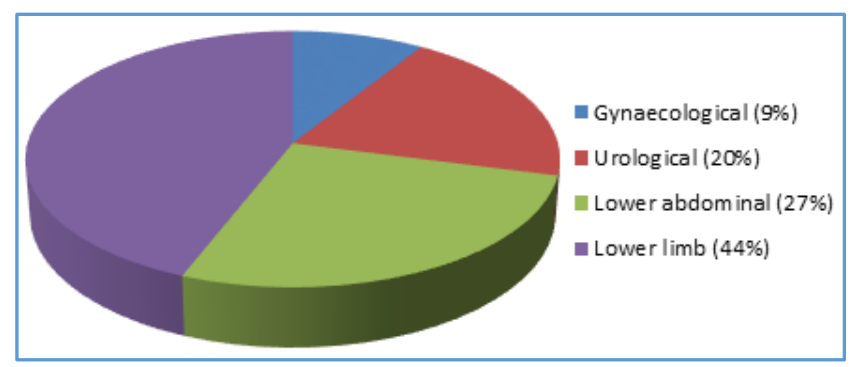

\begin{tabular}{|c|c|c|c|}
\hline $\begin{array}{c}\text { Parameter } \\
\text { observed }\end{array}$ & Group BF & Group BM & P value \\
\hline $\begin{array}{c}\text { Onset of } \\
\text { sensory block }\end{array}$ & $227.9 \pm 25.6 \mathrm{sec}$. & $223.6 \pm 35.5 \mathrm{sec}$. & 0.48 \\
\hline $\begin{array}{c}\text { Duration of } \\
\text { sensory block }\end{array}$ & $217.2 \pm 24.5 \mathrm{~min}$. & $216.7 \pm 28.1 \mathrm{~min}$. & 0.925 \\
\hline $\begin{array}{c}\text { Duration of } \\
\text { complete } \\
\text { analgesia }\end{array}$ & $211.9 \pm 26.8 \mathrm{~min}$. & $212.5 \pm 27.0 \mathrm{~min}$. & 0.91 \\
\hline $\begin{array}{c}\text { Duration of } \\
\text { effective } \\
\text { analgesia }\end{array}$ & $226.5 \pm 26.8 \mathrm{~min}$. & $228.5 \pm 30.1 \mathrm{~min}$. & 0.71 \\
\hline $\begin{array}{c}\text { Systolic blood } \\
\text { pressure mmHg } \\
\text { at } 60 \text { min. }\end{array}$ & $113 \pm 14.7$ & $111.68 \pm 11.1$ & 0.73 \\
\hline $\begin{array}{c}\text { Diastolic blood } \\
\text { pressure mmHg } \\
\text { at } 60 \text { min. }\end{array}$ & $72 \pm 8.9$ & $70.8 \pm 8.7$ & 0.73 \\
\hline $\begin{array}{c}\text { Heart rate (Per } \\
\text { min.) }\end{array}$ & $72.38 \pm 8$ & $72.82 \pm 8.28$ & 0.76 \\
\hline $\begin{array}{c}\text { Sp02\% at } 60 \\
\text { min. }\end{array}$ & $98.40 \pm 0.92$ & $98.46 \pm 0.95$ & 0.29 \\
\hline
\end{tabular}

\section{Side Effects}

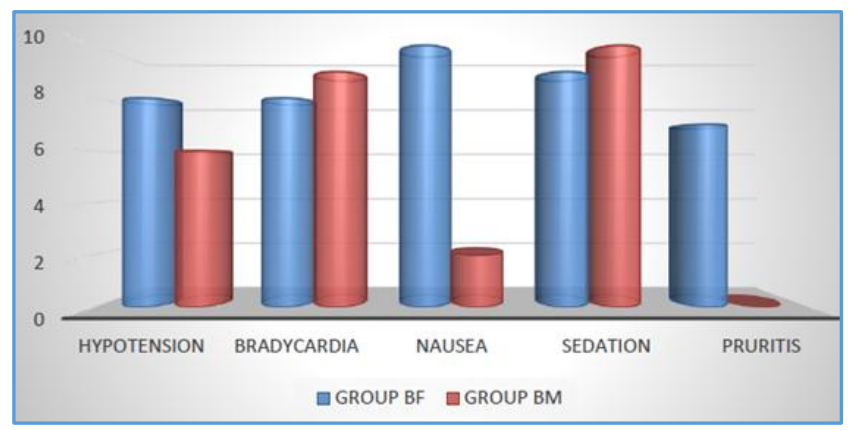

\section{Side Effects in both Groups}

Nausea occurred in 10 patients in BF group compared to 2 patients in BM group. The $\mathrm{p}$ value is 0.031 which shows statistical significance.

Pruritis incidence was 7 in BF group and no pruritis was observed in BM group ( $p$ value is 0.006 ).

\section{Sedation Score}

\begin{tabular}{|c|c|c|}
\hline Sedation Score & Group BF & Group BM \\
\hline One & 41 & 40 \\
\hline Two & 9 & 10 \\
\hline Three & 0 & 0 \\
\hline Four & 0 & 0 \\
\hline Five & 0 & 0 \\
\hline
\end{tabular}

$\mathrm{P}$ value is 0.79 .

\section{DISCUSSION}

The mean onset of sensory block in fentanyl group was 227.9 sec. and in midazolam group, mean onset of sensory block was $223.6 \mathrm{sec}$. Similar values were obtained with regard to the onset of sensory block in midazolam group in the studies conducted by Nidhi Agrawal et al ${ }^{11}$ in 2005 and Aikta Gupta et $\mathrm{al}^{12}$ in 2008. There were no differences between the two groups with respect to the onset of block as significance value obtained from independent sample's t test was more than 0.05 (here it is 0.487).

The mean duration of sensory block in group BF was 217.2 min and in group BM, mean duration of sensory block was $216.7 \mathrm{~min}$. There were no differences between the two groups with respect to the duration of block as significance value obtained from independent sample's t test was more than 0.05 (here it is 0.925 ).

The mean duration of complete analgesia in group BF was 211.9 min. and in group BM, mean duration of complete analgesia was $212.50 \mathrm{~min}$. There were no differences between the two groups with respect to the duration of complete analgesia as significance value obtained from independent sample's $t$ test was more than 0.05 (Here it is 0.912).

The mean duration of effective analgesia in group BF was $226.50 \mathrm{~min}$. with a standard deviation of 26.883 and in group $\mathrm{BM}$, mean duration of effective analgesia was $228.56 \mathrm{~min}$. with a standard deviation of 30.122 . There were no differences between the two groups with respect to the duration of effective analgesia as significance value obtained from independent sample's $t$ test was more than 0.05 (Here it is 0.719 ).

\section{Side Effects}

There were no significant differences between the two groups with respect to the occurrences of bradycardia, hypotension and in sedation scores as the significance values obtained from Fisher's exact test were more than 0.05 for each of these variables.

There were significant differences between the two groups with respect to the occurrence of nausea as the significance value obtained from Fisher's exact test was less than 0.05. Nausea was more commonly associated with fentanyl group though none of the patients in both groups developed vomiting.

$14 \%$ of people in fentanyl group developed pruritus whereas none in midazolam group developed it. The association of pruritus with fentanyl was statistically significant as the significance value from Fisher's exact test was less than 0.05 . Pruritus was mild and did not require any treatment. None of the patients in our study had any postoperative complications like urinary retention, 
respiratory depression, lower limb weakness or any other neurological deficits.

This study indicates that incidence of side effects such as nausea and pruritus are more common in fentanyl group compared to midazolam group and the differences between the groups in terms of these side effects were statistically significant.

\section{CONCLUSION}

The present study concludes that there were no differences in the onset and duration of sensory blockade, and durations of complete and effective analgesia, when fentanyl 25 micrograms or midazolam $1 \mathrm{mg}$ was used as an additive to intrathecal hyperbaric bupivacaine for spinal anaesthesia. But midazolam was associated with fewer side effects compared to fentanyl.

\section{REFERENCES}

[1] Fields HL, Martin JB. Pain-Pathophysiology and Management. In: Fauci AS, Braunwald E, Kasper DL, et al. Harrison's principles of internal medicine. $17^{\text {th }}$ edn. New York: McGraw Hill 2008:81-3.

[2] Dhummansure DV, Patil SG, Haque MM, et al. A comparative study of the effects of intrathecal bupivacaine $(0.5 \%)$ with clonidine $(1 \mu \mathrm{g} / \mathrm{kg})$ versus Intrathecal Bupivacaine (0.5\%) with fentanyl $(25 \mu \mathrm{g})$ for spinal anaesthesia. Journal of Evidence based Medicine and Healthcare 2014;1(13):1621-34.

[3] Sethi BS, Samuel M, Sreevastava D. Efficacy of analgesic effects of low dose intrathecal clonidine as adjuvant to bupivacaine. Indian $J$ Anaesth 2007;51(5):415-9.

[4] Kathirvel S, Sadhasivam S, Saxena A, et al. Effects of intrathecal ketamine added to bupivacaine for spinal anaesthesia. Anaesthesia 2000;55(9):899-904.
[5] Tan PH, Chia YY, Lo Y, et al. Intrathecal bupivacaine with morphine or neostigmine for postoperative analgesia after total knee replacement surgery. Can J Anaesth 2001;48(6):551-6.

[6] Singh V, Gupta LK, Singh GP. Comparison among intrathecal fentanyl and butorphanol in combination with bupivacaine for lower limb surgeries. J Anaesth Clin Pharmacol 2006;22(4):371-5.

[7] Patra P, Kapoor MC, Gordon T, et al. Spinal anaesthesia with low dose bupivacaine and fentanyl for endoscopic urological surgeries. J Anaesth Clin Pharmacol 2005;21(2):147-54.

[8] Gupta A, Prakash S, Deshpande S, et al. The effect of intrathecal midazolam $2.5 \mathrm{mg}$ with bupivacaine on postoperative pain relief in patients undergoing orthopedic surgery. J Anaesth Clin Pharmacol 2008;24(2):189-92.

[9] Biswas BN, Rudra A, Bose BK, et al. Intrathecal fentanyl with hyperbaric bupivacaine improves analgesia during caesarean delivery and in early postoperative period. Indian J Anaesth 2002;46(6):469-72.

[10] Nemethy M, Paroli L, Williams-Russo PG, et al. Accessing sedation with regional anaesthesia: interrater agreement on a modified Wilson sedation score. Anaesthesia Analgesia 2002;94(3):723-8.

[11] Agrawal N, Usmani A, Sehgal R, et al. Effect of intrathecal midazolam bupivacaine combination on post-operative analgesia. Indian J Anaesth 2005;49(1):37-9.

[12] Bharti N, Batra YK, Negi SL. Efficacy of intrathecal midazolam versus fentanyl for endoscopic urology surgery. South Afr J of Anaesth Analg 2015;21(2):314. 